\title{
Acute hydrocortisone myopathy in acute severe asthma
}

\author{
ALAN J KNOX, B HUGO MASCIE-TAYLOR, MARTIN F MUERS \\ From the Department of Respiratory Medicine, St James's University Hospital, Leeds
}

Myopathy of insidious onset produced by corticosteroids is well recognised. In recent years acute myopathy has been reported in patients with acute severe asthma treated with 3-4 $\mathrm{g}$ of intravenous hydrocortisone a day. ${ }^{12}$ It has been argued that to minimise the risks of this the dose should be no more than $1 \mathrm{~g}$ of hydrocortisone a day. ${ }^{2}$ There is evidence that $1 \mathrm{~g} /$ day is an effective regimen. ${ }^{3}$ We report a further case of acute myopathy occurring in a patient who never received more than $1 \mathrm{~g} /$ day of intravenous hydrocortisone. We suggest that even with a $1 \mathrm{~g} /$ day regimen physicians should be aware of the possibility of myopathy developing if a patient is found to be slow to be weaned off ventilation.

\section{Case report}

A 15 year old girl was admitted to hospital with a two day history of increasing dyspnoea. She had been asthmatic from the age of 2, requiring several hospital admissions during one of which she had required artificial ventilation. Her usual maintenance treatment was terbutaline and budesonide by inhaler, and oral theophylline. On examination she was unable to speak, tachypnoeic, and centrally cyanosed, and had a heart rate of 120 beats/min and evidence of severe airways obstruction. Peak flow was unrecordable. Arterial blood gases while she was breathing $35 \%$ oxygen showed an arterial oxygen saturation of $10 \mathrm{kPa}$ $(75 \mathrm{~mm} \mathrm{Hg})$, an arterial carbon dioxide tension of $7.17 \mathrm{kPa}$ $(54 \mathrm{~mm} \mathrm{Hg})$ and a $\mathrm{pH}$ of 7.27 . A chest radiograph was normal. She was treated with intravenous hydrocortisone $200 \mathrm{mg}$, intravenous aminophylline $250 \mathrm{mg}$, nebulised salbutamol $5 \mathrm{mg}$, and high flow oxygen. She did not improve and required artificial ventilation.

She was slow to respond to treatment, with high inflation pressures (up to $65 \mathrm{~cm} \mathrm{Hg}$ ) and severe airways obstruction. She required artificial ventilation for 10 days. Her treatment consisted of $1 \mathrm{~g} /$ day hydrocortisone, chlorpromazine $6 \mathrm{mg} /$ hour, promethazine $3.2 \mathrm{mg} /$ hour, pethidine $12 \mathrm{mg} /$ hour, and aminophylline $800 \mathrm{mg} / \mathrm{day}$, all intravenously, and nebulised salbutamol $5 \mathrm{mg}$ six hourly. As she was slow to respond, an infusion of salbutamol $0.3 \mathrm{mg} /$ hour and inhalations of nebulised ipratropium $1 \mathrm{ml}$ six hourly were added. She was never given more than $1 \mathrm{~g}$ of hydrocortisone a day, and received a total of $10 \mathrm{~g}$. On resumption of spontaneous respiration she was noted to have appreciable muscle weakness, mainly in the upper limbs, affecting both proximal and distal muscle groups. She was unable to

Address for reprint requests: Dr AJ Knox, Department of Respiratory Medicine, St James's University Hospital, Leeds 9. lift her hands above her head. Reflexes were normal. There was no sensory component. Serum creatine kinase activity was normal. Electronic myography examination of the right deltoid, right extensor digitorum communicis, right first dorsal interosseous, and right tibialis anterior muscles showed that all of the muscles were silent at rest, with frequent short duration polyphasic potentials on contraction, indicating an extensive myopathy affecting both proximal and distal muscle groups. Her weakness improved over the next week. On discharge from hospital 10 days later she had full power in all four limbs. Her peak expiratory flow was 380 litres a minute.

Her asthma has remained well controlled with inhaled terbutaline and inhaled corticosteroid treatment, and she has had no recurrence of her muscle symptoms or signs. Further electromyographic examination six months later, however, still showed evidence of mild myopathy.

When her records were reviewed it was noted that she had required ventilation on one previous occasion. At that time she had been treated with $1 \mathrm{~g}$ of hydrocortisone a day for five days, without developing muscle disorder. Her treatment had otherwise been identical.

\section{Discussion}

There are only two previous single case reports of acute hydrocortisone myopathy occuring in acute severe asthma. ${ }^{12}$ There are similarities between our case and both of these. The distribution of the muscle weakness was both proximal and distal, in contrast with the proximal myopathy of chronic steroid treatment. In each case there was difficulty in breathing after withdrawal of artificial ventilation, despite resolution of airways obstruction. In each case there was concomitant administration of intravenous salbutamol. Of the two other reported cases, electromyography showed abnormal features in one ${ }^{1}$ and serum creatine kinase activity was abnormal in the other. ${ }^{2}$ Muscle biopsy in one showed changes similar to experimental corticosterone myopathy, ${ }^{2}$ a condition induced in animals, where massive glycogen accumulation is a characteristic ultrastructural feature. ${ }^{4}$ Our patient had normal serum creatine kinase activity but a very abnormal electromyogram. We did not perform a muscle biopsy. Both of the previous patients had received larger daily doses of hydrocortisone than our patient, receiving in one case $4 \mathrm{~g} /$ day maximum and reduced doses for 20 days $^{2}$ and in the other $3 \mathrm{~g} /$ day for an unspecified number of days, ${ }^{1}$ whereas our patient had never received more than $1 \mathrm{~g} /$ day and received $10 \mathrm{~g}$ in total. Our patient improved much more rapidly than the others, which may have been because she received less hydrocortisone. She had not developed myopathy when previously treated with a smaller dose of hydrocortisone ( $5 \mathrm{~g}$ in total), which suggests that acute hydro- 
cortisone myopathy may be dose related in susceptible individuals.

\section{References}

1 Macfarlane IA, Rosenthal FD. Severe myopathy after status asthmaticus. Lancet 1977;ii:615.
2 Van Marle W, Woods KL. Acute hydrocortisone myopathy. Med J 1980;281:271-2.

3 Collins JV, Clark TJH, Brown D, Thorenson J. The use of cort costeroids in the treatment of acute asthma. $Q J$ Med 197f? 44:259-73.

4 Affifi AK, Bergman RA. Steroid myopathy. A study of the evov lution of the muscle lesion in rabbits. Johns Hopkins Med J 1969 124:66-86.

\section{Book notices}

Airway Responsiveness: Measurement and Interpretation. (proceedings from a workshop held at Mont Ste Marie, Quebec, June 1983). Ed FE Hargreave, AJ Woolcock. (Pp 146; free of charge.) Astra Pharmaceuticals Canada Ltd. 1985. ISBN 0-921063-02-5.

The measurement of airway responsiveness has become so common in clinical and particularly respiratory research practice that a thorough overview and stocktake of current procedures has been greatly needed. This readable and fairly slim volume fits the bill as well as could be reasonably expected. The publication of workshop proceedings has become a very fashionable pastime over recent years and so frequently the end result is disjointed and spoiled by tedious, poorly edited, and often verbatum discussion. Fortunately, this production has avoided most of these pitfalls. With 17 different papers covering a range of interest from the highly theoretical to the pragmatic use of equipment, there is inevitably some variation in subjective interest in the individual parts. The whole work, however, is given great strength and cohesion by being interspersed with excellently edited discussion and review sections that summarise the thoughts of the workshop, and, without being unduly didactic, try to formulate some realistic and practical conclusions. Perhaps pre-eminent among these discussion sections is that by JE Fish, who sounds a death knell for the use of exercise as a challenge procedure in the face of more effective and quantitative methods. He quite rightly emphasises the importance of more adequate reporting of both methods and results in scientific papers-so frequently one is unable to relate one author's experience with that of others because of inadequate details. Editors and reviewers, please take note! Authors, too, should take note of the fact that at last the term "airway responsiveness" has succeeded in replacing the outmoded term "bronchial reactivity." It has been evident for several years that this should occur as "bronchial reactivity" is anatomically inappropriate and the term was concurrently being used with both a general and a specific meaning. The book ends with two pages of very useful, specific, and practical recommendations. These may be weakly criticised for not quantifying sufficiently what should be regarded as adequate within subject reproducibility. This has become pre-eminently important in studies of mechanisms of change in individual responsiveness. In cone clusion, this welcome state of the art work should become handbook for all those, clinicians and investigators, who are using, or intend to use, airway challenge techniques asthma.-EHW

Sleep and its Disorders. JD Parkes. (Pp 499; £29.50.) Saunders. 1985. ISBN 0-7216-1858-8.

This book is not aimed primarily at the respiratory phys cian. It comes from a series entitled "Major Problems Neurology" and the author is a reader in neurology King's College Hospital and the Institute of Psychiatry London. Thus it offers a different slant on sleep disorders from that prevalent in publications on sleep in relation 8 breathing, and this enhances its value to the respiratory physician who is interested in sleep problems. The 500 pages arge divided into three sections, about one third on the phys iology of normal sleep, including its relation to circadian rhythms, one half on disorders of sleep and the rest on slees pharmacology. The book is very well referenced throughout, the 10 chapters having an average of 270 references a chap ter. Indeed, one of the most important functions of this bod so far as the respiratory physician reader is concerned would be as a source of references. The $\mathbf{4 0}$ page section on narcolepsy will be found particularly useful by those interest in sleep apnoea. Reports in this area have been confused, many of the older series of narcoleptic patients containes patients who would now be recognised as having the sleep apnoea syndrome. Dr Parkes has a particular interest in naco colepsy, however, and this section is clear and helpful. THE 70 page section on respiratory disorders during sleep is commendable attempt by a neurologist to cover this arę. Some minor points may be debatable - such as the term "subobstructive apnoea" and the bland statement th "some old people must die in their sleep as a consequence of sleep apnoea." Overall, however, the section is well written and has obviously resulted from much very hard work. think that respiratory physicians interested in sleep wi enjoy this book, and they will certainly discover many ne and useful references.-NJD 